\title{
Police Misconduct: Mapping its location, seriousness and theoretical underpinning
}

\author{
Moss, B
}

Author post-print (accepted) deposited by Coventry University's Repository

Original citation \& hyperlink:

Moss, B 2017, 'Police Misconduct: Mapping its location, seriousness and theoretical underpinning' Policing: A Journal of Policy and Practice. , vol (in press), pp. (in press)

https://dx.doi.org/10.1093/police/pax077

DOI 10.1093/police/pax077

ISSN 1752-4512

ESSN $1752-4520$

Publisher: Oxford University Press

This is a pre-copyedited, author-produced version of an article accepted for publication in Policing following peer review. The version of record Moss, B 2017, 'Police Misconduct: Mapping its location, seriousness and theoretical underpinning' Policing: A Journal of Policy and Practice. , vol (in press), pp. (in press) is available online at: https://dx.doi.org/10.1093/police/pax077

Copyright $(\odot$ and Moral Rights are retained by the author(s) and/ or other copyright owners. A copy can be downloaded for personal non-commercial research or study, without prior permission or charge. This item cannot be reproduced or quoted extensively from without first obtaining permission in writing from the copyright holder(s). The content must not be changed in any way or sold commercially in any format or medium without the formal permission of the copyright holders.

This document is the author's post-print version, incorporating any revisions agreed during the peer-review process. Some differences between the published version and this version may remain and you are advised to consult the published version if you wish to cite from it. 


\title{
Police Misconduct: mapping its location, seriousness and theoretical underpinning
}

\author{
Introduction
}

This article draws attention to the geography of police officer misconduct. The basis for doing so rests in the uneven manner by which police officers have been found to view areas, target inhabitants as crime suspects, treat them when victims of crime and interact with them relative to other areas (Sun et al., 2008; Rossler and Terrill, 2012). Such areas have tended to be characterised by high deprivation and low social capital (Loftus, 2012) and have given rise to numerous complaints, particularly concerning the use of excessive force by police officers (Lersch, 1998). The value of understanding police officer misconduct geography, meanwhile, rests in ensuring good policing and its legitimacy over time. Despite this, the topic has received little scholarly attention (Lersch, 1998 is an exception) with state agencies producing overviews of the geographical spread of complainants (CND, 2008; NYCCRB, 2008) or a description of most common incident location types (PONI, 2013; GSOC 2013 ${ }^{1}$ ), but little more.

\section{Study Context}

The Irish Republic relied upon in this article presented a useful frame through which to explore the geography of police officer misconduct for several reasons. First, sustained concerns about individual and group misconduct by Irish police officers at the turn of the $21^{\text {st }}$ century (see Morris, 2004) led to the introduction of a new architecture for the management, inspection, and oversight of the national police agency -the Garda Síochána- through the Garda Síochána Act 2005. This legislation included the creation of the Garda Síochána Ombudsman Commission (GSOC) to investigate complaints against police officers (called 
gardaî) independently of the unitary, national police agency, with GSOC commencing operations in May 2007.

Second, prior representations of police officer misconduct, such as theft, bribery, sexual assaults, and road traffic matters have drawn upon diverse labels to frame it. These have included deviance, misbehaviour, corruption, integrity, probity transgressions, and ethical dilemmas (Chappell and Piquero, 2004; Dean et al. 2010; Newburn, 2014). In the Irish case, at least on paper the 2005 Act brought clarity to garda misbehaviour, defining it as an 'offence' or a 'breach of discipline'. The latter covers nine actions, which, if proven, could incur a sanction under the separate Discipline Regulations 2007 with the regulations in turn seeming to distinguish between lesser and more serious misbehaviour through provision for lesser and more serious sanctions of verbal warnings, monetary fines, or dismissal.

A third reason for the use of the Irish model is that the current and former police oversight agencies have differed over whether alleged police officer misbehaviour occurs in some geographic areas more or less frequently than in others. GSOC, for its part, stated that for each business year 2010-2013 complainants had not come from categories of greatest social disadvantage. This finding contradicted that of its predecessor, the Garda Síochána Complaints Board (GSCB), which had been operational from 1987 to April 2007. The GSCB had stated at the end of its first operational year that complaints were in fact heavily concentrated in areas of greatest economic and social deprivation (GSCB, 1988).

The current article took this discrepancy as its starting point and looked to probe the subject matter of police complaint geography and do so by relying upon an appropriate theoretical framework. Shaw and McKay's social disorganization theory (1969) offered a good starting 
point through which to achieve this. The researchers argued that ecological conditions, such as structural density, and socio-economic conditions, such as poverty and residential mobility, shaped local delinquency rates over and above the characteristics of individual residents in what they termed 'low neighbourhoods'. These conditions inhibited an area's capacity to regulate itself, e.g. to realise informal control over deviance though collective action so as to reduce its occurrence. Shaw and McKay determined that the primary variables explaining deviance were areas populated by those reliant on income supports and immigrant and non-white households and presence of non-owner housing tenure. Subsequent studies of crime geography framed in terms of social disorganization have confirmed the validity of the original theoretical approach. However, as pointed out by Kubrin and Weitzer (2003), later studies have largely omitted discussion of the role of formal social control, e.g. local government, and police agencies, in controlling deviance on the ground.

Consequently, this article aimed to inquire into the role of formal social control, specifically police officers, in generating local deviance as captured in misconduct allegations relating to low neighbourhoods in Ireland. In doing this a distinction was made between (i) the areas that submitted higher volumes of police complaints and (ii) where complained about incidents involving police-public interactions had occurred. A difference between (i) and (ii) took its cue from existing studies of crime and place. Such studies have addressed how offenders travelled to commit crime, how incidents reduced in volume the further they were located from an offender's residence (Rengert et al., 1999), a process called 'distance decay', and that incident seriousness diminished with increased distance from an offender's residence (Chamberlain and Hipp, 2015). Studies of police officer misconduct to date, by contrast, have not addressed these items. 


\section{Research Questions}

Arising from the above considerations, four research questions were addressed. Namely:

1. did complaints to GSOC predominantly arise in low neighbourhoods?

2. did most complaint incidents occur within the immediate vicinity of the complainant residence?

3. did allegation seriousness decline the greater the distance from a complainant's address?

4. was there any concentration of more serious allegation types in low neighbourhoods compared to others?

\section{Data and Methods}

To answer these questions complaints from among the 13,000 processed by the Irish police complaints agency GSOC between 2007 and 2013 were analysed. As complaints can contain one or more allegations, a single allegation was selected at random from each complaint. The measures of interest within complaint records, thereafter, were socially disorganized neighbourhoods, policing boundaries, markers of complaint geography and allegation types. The idea of socially disorganized or low neighbourhoods here married Shaw and McKay's primary measures of social disorganization with a measure of directed police attention that could result in greater police-public interaction possibilities and therefore more instances of alleged police misbehaviour. A proxy measure of this form was present in Ireland in the guise of the RAPID programme. This was the main Irish Government instrument through which deprivation alleviation was to be targeted at a local level from 2001 to 2021 . RAPID targeted the 46 most disadvantaged urban areas and provincial towns, each determined by deprivation level, volume of local authority/social housing stock and schools designated as disadvantaged by central government (Fitzpatrick Associates, 2006), and identification of concentrated disadvantage by local partnerships and local governments. Issues of crime, crime prevention, 
youth diversion from crime and strained police-public relations were visible, initial RAPID goals. Furthermore, when introducing the 2005 Act to reform domestic policing, the Irish parliament debated these same issues in the context of RAPID areas, not other boundary arrangements (Oireachtas, 2004).

Turning to the chosen policing unit, the low neighbourhoods were analysed within the frame of individual Garda stations (i.e. police precincts). These were preferable, for instance, to the construction of 'natural areas' (Smith et al., 2001) whose relationship to socio-demographic data for the entire area in which deviance was reported was not made explicit. In a further step, mirroring earlier spatial studies (Bruinsma, 2007), three Garda stations -Scotsburg, Hometown and Duville ${ }^{2}$ - were chosen for analysis. These were located within different Garda divisions from one another. Additionally, each contained at least one RAPID catchment area ${ }^{3}$ and a range of areas of varying socio-economic profile from 'very affluent' to 'very disadvantaged', as measured by the Kelly and Teljeur national deprivation index (2013). Based on Shaw and McKay's primary factors, among the three stations Duville had the least and Hometown the most socially disorganized profiles (Table 1).

Table 1.

Scotsburg, Hometown and Duville profiles

\begin{tabular}{|l|l|l|l|l|}
\hline & $\begin{array}{l}\text { Median } \\
\text { All Garda } \\
\text { Stations } \\
\text { Nationally } \\
(\mathbf{n = 5 6 3 )}\end{array}$ & Scotsburg & Hometown & Duville \\
\hline Unemployment & $11 \%$ & $12 \%$ & $14 \%$ & $12 \%$ \\
\hline $\begin{array}{l}\text { Household } \\
\text { Occupancy Type - } \\
\text { Private Rental }\end{array}$ & $10 \%$ & $37 \%$ & $52 \%$ & $26 \%$ \\
\hline $\begin{array}{l}\text { Household } \\
\text { Occupancy Type- } \\
\text { Local Authority }\end{array}$ & $6 \%$ & $16 \%$ & $13 \%$ & $6 \%$ \\
\hline
\end{tabular}




\begin{tabular}{|l|l|l|l|l|}
\hline Rental & & & & \\
\hline $\begin{array}{l}\text { Household } \\
\text { mobility in last 12 } \\
\text { months }\end{array}$ & $4.9 \%$ & $15 \%$ & $20 \%$ & $9 \%$ \\
\hline $\begin{array}{l}\text { Socio-Economic } \\
\text { Status- } \\
\text { 'Professional' }\end{array}$ & $5.9 \%$ & $8 \%$ & $7 \%$ & $9 \%$ \\
\hline Unskilled & $4 \%$ & $5 \%$ & $6 \%$ & $3 \%$ \\
\hline $\begin{array}{l}\text { Non-White } \\
\text { Population* }\end{array}$ & $97.3 \%$ & $15 \%$ & $16 \%$ & $17 \%$ \\
\hline $\begin{array}{l}\text { Deprivation } \\
\text { Decile** }\end{array}$ & 9 & 9 & 9 & 9 \\
\hline Crime Decile & & 3 & 3 & 7 \\
\hline Complaint Decile & & 3 & 3 & 7 \\
\hline
\end{tabular}

Notes: *Based on Small Area Population Statistics at Garda Station level; ** based on own calculations from National Deprivation Index (Kelly and Teljeur, 2012)

These and national level Census data are drawn upon in the Discussion section below to provide a summary of the contribution of social disorganization to understanding police complaint patterns.

Next, three forms of geographic markers within complaints were analysed. The first one, each complainant's address, here called the complaint emission point, denoted location of households submitting a complaint to GSOC. Thereafter complained-about incident locations signified where the garda-public interaction had occurred that had given rise to the complaint. Complaint emission point has almost exclusively been drawn upon in academic and political discussions to signify locations of troubling police officer conduct. However, it has not been demonstrated that where complaints arose was necessarily the same as where they occurred and what this revealed about policing locally. To address this, an analysis of the possible differences between complaint emission and incident location points was performed using ESRI ArcGIS digital mapping software (version 10.1), relying upon co-ordinates to map each emission and incident location point. The distance between such points was treated as an interval variable and measured in metres. Finally, whether each emission or incident location 
point had occurred in a RAPID or non-RAPID area was determined by reference to catchment areas then in place; this variable taking the form of a dichotomous one (Yes/No). Four hundred and forty-five GSOC complaints from a possible 776 provided both emission and incident location points (Scotsburg $n=114$; Hometown $n=117$; and Duville $n=214$ ). This number was sufficient to portray a valid pattern of alleged police misconduct in the selected stations.

The nature of allegations contained in complaints was determined by the descriptive label in the GSOC database, this detail missing for some of the 445 complaints. While GSOC had adopted 18 possible allegation type labels over the period 2007-2013, just four types accounted for $80 \%$ of allegations in that time. These were discourtesy, neglect of duty, abuse of authority -i.e. oppressive conduct without good cause- and non-fatal offences against the person (assault). Given this, all other allegation types were recorded here as 'Other'. Excluding the blank and 'Other' allegations left 378 complaints for initial analysis, with allegation type treated as an ordinal variable and the four allegation types used assigned values 1-4 throughout. This approach reflected increasing seriousness in terms of the penalties under the 2007 Regulations, as mentioned in the Study Context section above, and it also reflected the nature of the increasingly serious investigative phase that had been applied by GSOC to examine such allegation types in the years 2007-2013. Whereas discourtesy allegations, for instance, where commonly considered for informal resolution, at the upper end allegations of assault by police officers were investigated as possible criminal offences.

Determination of distance decay in allegation type seriousness the greater the emissionincident point distance was judged by surrounding the individual RAPID areas in each map with two 500-metre buffers. These zones indicated distances of 500 and 1,000 metres outside 
the RAPID area and resembled that approach developed by Sutherland (1940) and enhanced by Shaw and McKay and Robitaille et al. (2011) to show crime concentrations and variations. Using the buffer tool in effect split each station into three parts, namely the RAPID area, the next adjacent area, and that part of the station catchment area furthest from the RAPID area. The numeric format of this variable and the others above signals that the overall analytical approach was a quantitative one. Further, reflecting this quantitative approach, various statistical tests were used to examine the interplay between allegation types, distances between emission and incident location points and RAPID/non-RAPID locations. The relevance of the test results, set out in the Findings section below to the article's overall conclusions was that they indicated the likely occurrence of similar patterns across all 600Garda stations then in operation. Additionally, using mapping software in the manner described represented an original approach to analysis of alleged police officer misconduct in Ireland $^{4}$.

\section{Findings}

Looking to the first research question about where most complaints arose at station (precinct) level, Figures 1, 2 and 3 revealed that RAPID and non-RAPID areas were sources of complaints in each station.

Figure 1

Complaint Emission Scotsburg 


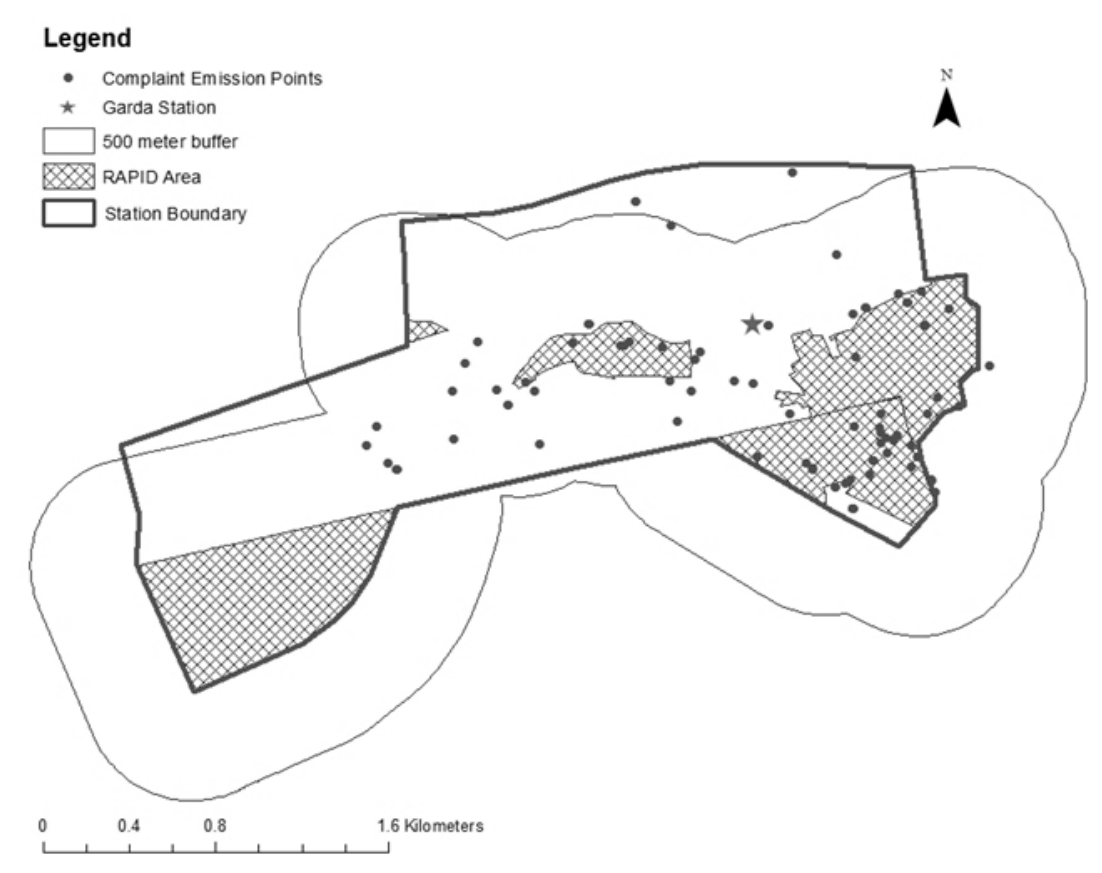

Note: The most easterly emission point in Scotsburg appeared outside the station boundary area. This was not an error, highlighting some of the problems of mapping boundaries.

Figure 2

Complaint Emission Hometown 


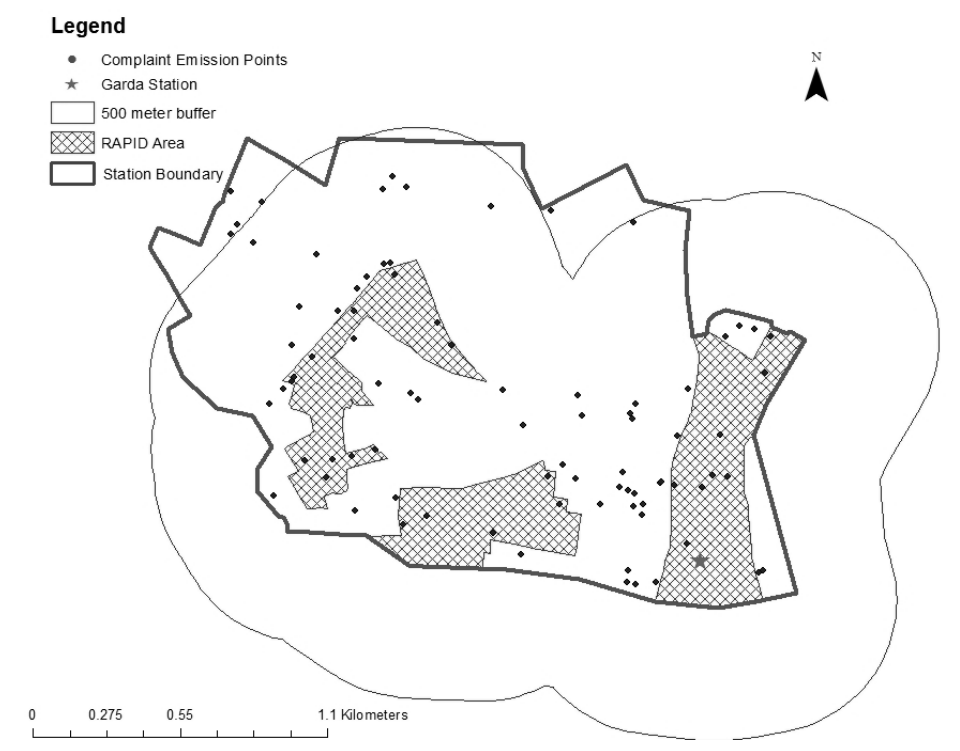

Figure 3

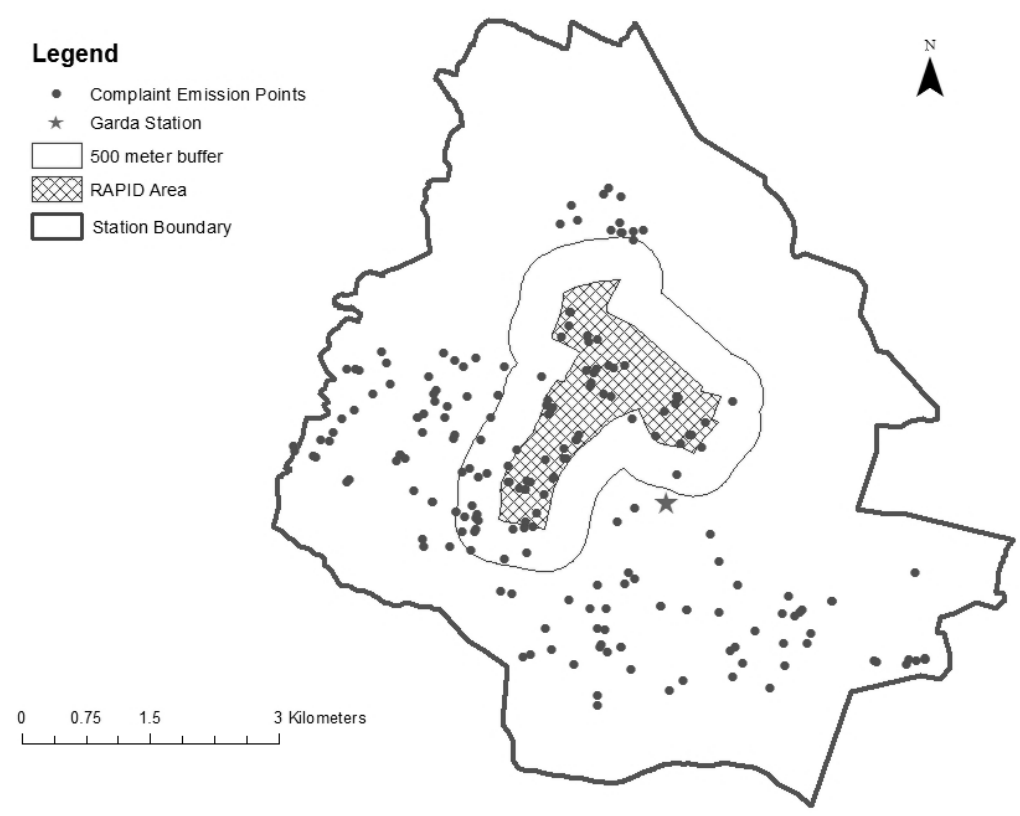

RAPID addresses accounted for 44\%, $28 \%$ and $25 \%$ of complaint emission in Scotsburg

(Figure 1), Hometown (Figure 2) and Duville (Figure 3) station areas respectively $(\mathrm{n}=50,33$ and 52). As given, the complaint emission results suggested that the proportions of complaints arising in RAPID areas were not a majority feature in each station. 
The second research question was concerned with how many incidents had occurred in the immediate area of the complainant address (a distance of 500 metres or less). It transpired that emission and incident location points were coterminous, i.e. located at the same point, in 85 of the 378 cases used (24\%). This result meant that most complaints (76\%) occurred at a remove from the complainant residence. When measured using the Euclidean approach or "as the crow flies", the median distance, that recorded by at least half of the cases, between complainant residence and incident location turned out to be greater than 1,250 metres. In fact, $71 \%$ or more of all incidents had occurred 501 metres or more beyond a complainant's home address (Table 2).

Table 2

\section{Emission-Incident Distances}

\begin{tabular}{|l|l|l|l|l|l|l|}
\hline $\begin{array}{l}\text { Emission-incident } \\
\text { location distance }\end{array}$ & \multicolumn{2}{|c|}{ Scotsburg } & \multicolumn{2}{c|}{ Hometown } & \multicolumn{2}{c|}{ Duville } \\
\hline $\begin{array}{l}\text { Emission to Incident } \\
\text { point distance }\end{array}$ & RAPID & Not & RAPID & Not & RAPID & Not \\
\hline $0-500$ metres & $21(42 \%)$ & $12(19 \%)$ & $10(40 \%)$ & $25(27 \%)$ & $21(39 \%)$ & $22(14 \%)$ \\
\hline $501-1,000$ metres & $7(14 \%)$ & $0(0 \%)$ & $3(12 \%)$ & $14(15 \%)$ & $5(9 \%)$ & $5(3 \%)$ \\
\hline $1,001+$ metres & $22(44 \%)$ & $52(81 \%)$ & $12(48 \%)$ & $53(58 \%)$ & $28(52 \%)$ & $133(83 \%)$ \\
\hline Total & 50 & 64 & 25 & 92 & 54 & 160 \\
\hline $\begin{array}{l}\text { Median Distance } \\
\text { metres }\end{array}$ & 1,428 & 1,256 & & 2,815 \\
\hline
\end{tabular}

This suggested that few of the complaints examined related to local policing. Distinguishing between the three stations, coterminous emission-incident points and shorter emissionincident point differences were most common in Scotsburg (20\%) and in RAPID areas (Table 
2). This finding indicated that complaints about local policing were more common in low neighbourhoods and in the Garda station that had the most resource deficient profile.

The third research question had sought to determine whether there was any reduction in allegation seriousness as the emission-incident distance grew. A spearman correlation test was used to measure the existence of any such relationship between allegation types and emission-incident distances. This test was appropriate on the basis that allegation type had been constructed as an ordinal variable while emission-incident distance had been arranged as an interval one. The result (rho $=-0.12, \mathrm{p}=0.05$ ) suggested that the relationship was negative and statistically significant, meaning that as emission-incident distance -that distance between complainant residence and incident location- increased allegation seriousness declined in value.

The fourth research question had sought to determine any concentration of allegation types within Garda station boundaries. One approach was to compare the values of allegation types based on whether the emission point was a RAPID or non-RAPID area. A Wilcoxon MannWhitney test, measuring the mean values of allegations in RAPID and non-RAPID areas, was used to do this. It produced a significant difference $(n=262$ and $n=120 ; z=-2.134, p=$ 0.382). RAPID areas achieved the higher actual rank (262) meaning that GSOC tended to rank complaints from RAPID areas as containing more serious content than those from nonRAPID areas.

An alternative approach compared allegation seriousness based on incident location points, arguably the truer geographic location of alleged police officer misconduct. This was performed using a Local Moran's I test, a test measuring clustering of high/low values on 
weighted features. Here the weighted feature was allegation type that had been assigned values 1-4. Reflecting the article's interest in policing conducted within single station areas, the test was only applied to incident points that had occurred within the stations' boundaries $(n=190$ complaints from the original 378 complaints). Test results are shown below (Figures 4, 5 and 6).

Figure 4

\section{Local Moran's I- Scotsburg Incidents}

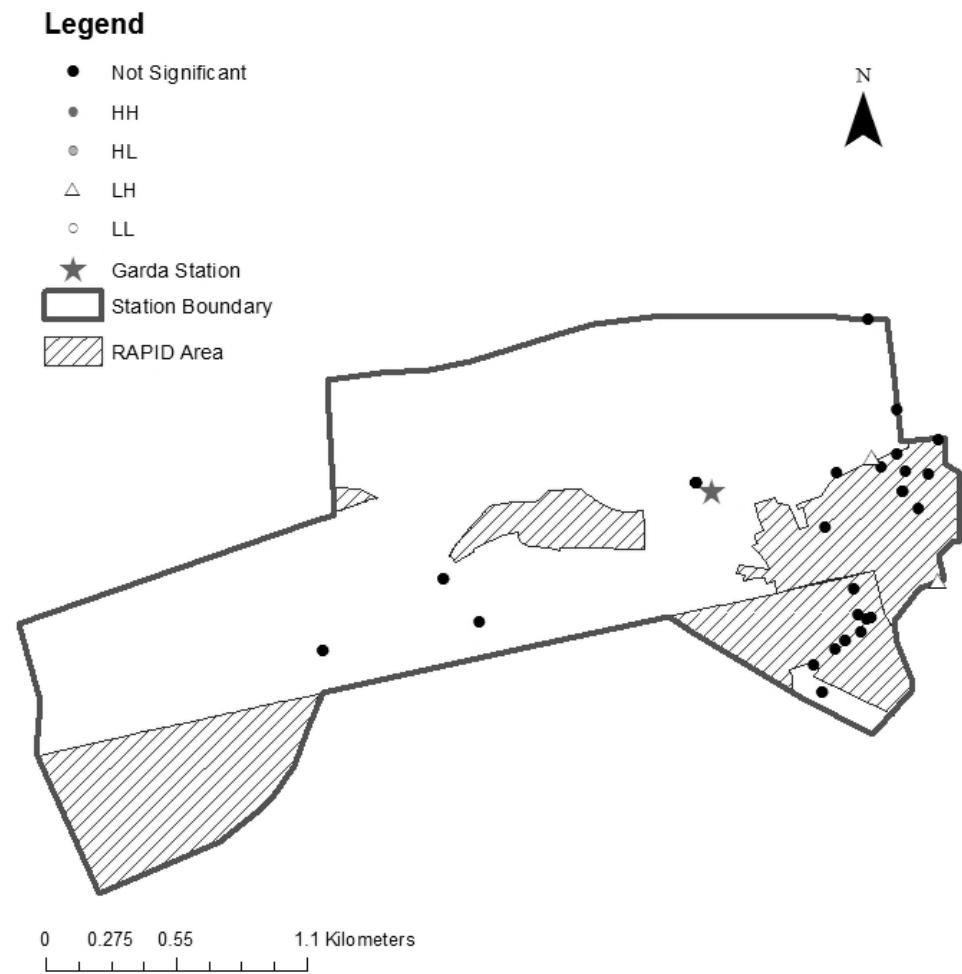

Figure 5

Local Moran's I- Hometown Incidents 


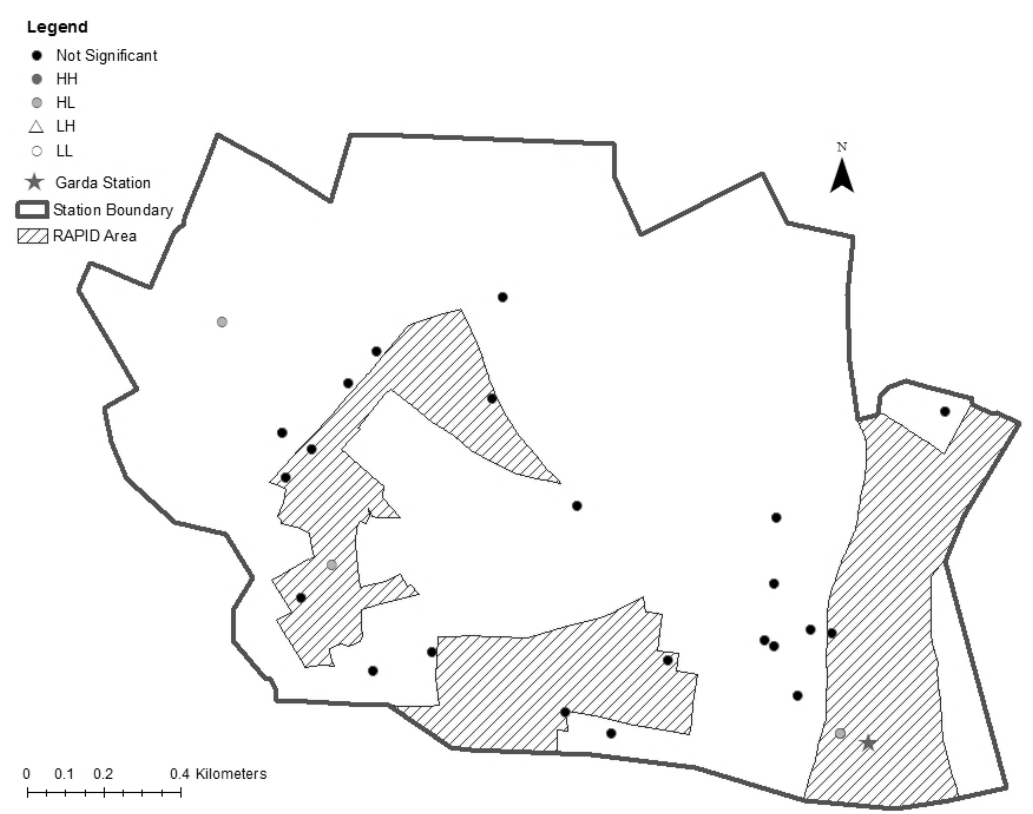

Figure 6

\section{Local Moran's I- Duville Incidents}

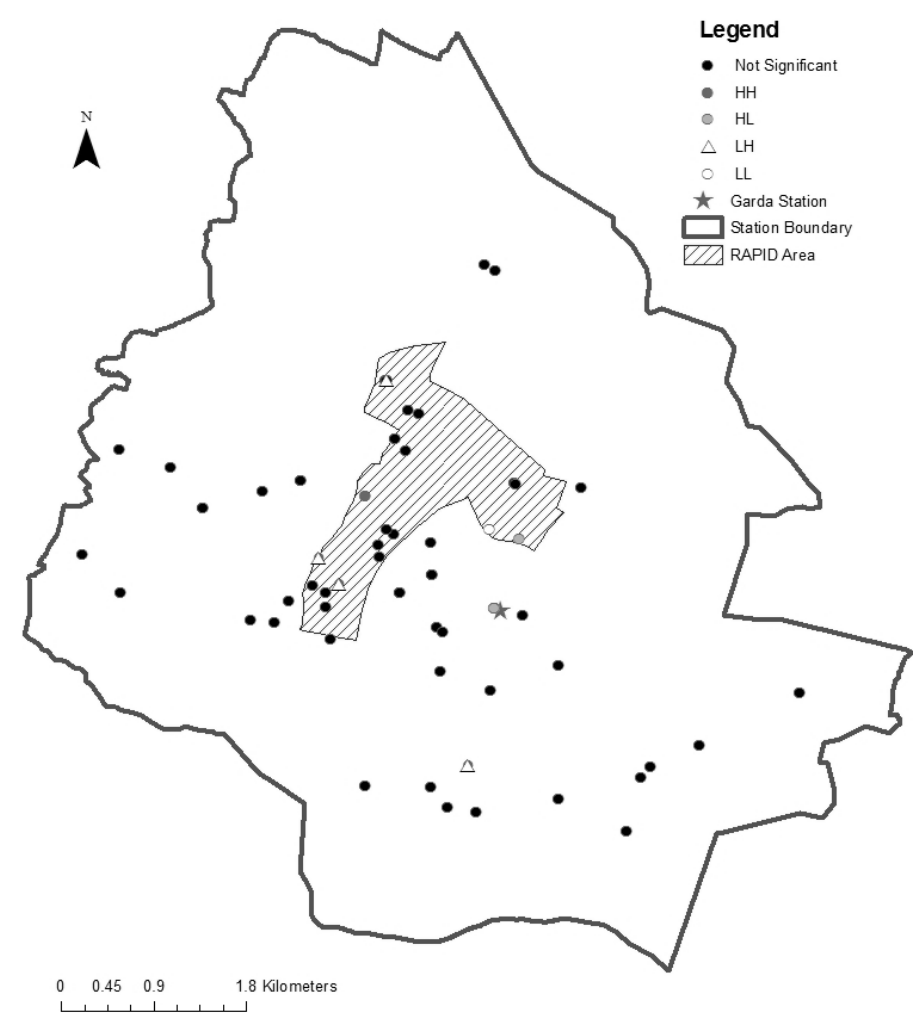


These reveal that RAPID areas were the most common sites of High-Low or Low-High allegation values in Scotsburg, Hometown and Duville, suggesting the presence of more serious allegation type values in the low neighbourhoods. However, across the three police stations allegation type clustering was the exception (Duville) rather than the norm. Most incident points returned a 'Not significant' result, implying little evidence of clustered garda misbehaviour overall.

\section{Discussion}

An appreciation of the geography of crime constitutes an important and sustained element of policing operations and academic discussion (see Steenbeek and Weisburd, 2016). Analysis of the geography of police officer misconduct, by contrast, generally remains neglected and devoid of sustained efforts to theorise it. Consequently, researchers and practitioners have overlooked possible signifiers of troubling police officer practice locally, until now. The first research question addressed here determined that the most socially disorganized neighbourhoods were not a majority source of complaints in any station. The proportion of complaints these areas did produce seemed explicable in Scotsburg and Hometown stations by reference to the proportion of the stations' physical area taken up by a public support programme ( $31 \%$ and $24 \%$ respectively) rather than any targeting by police officers assigned there. Further, targeting of a neighbourhood by police officers, much discussed in existing studies, seemed to have relevance in relation to one station only (Duville). Its RAPID area produced a complaint load some four times greater than the RAPID land coverage and associated population there would have suggested (24\% versus $6 \%$ ). Based on complaint emission point, therefore, the findings meant that low neighbourhoods were not the primary source of complaints at local level. 
Turning to the second research question regarding where the complained about incident had occurred, most complaints did not occur within the immediate vicinity of a complainant's home. Rather, most complaints occurred 1,000 metres or more from their address. This finding suggested that there was little evidence of localised police officer misconduct among the complaints examined. Future research on police complaints might improve upon this by using a greater volume of complaint data as well as details on place, complaint type, police officer complained about and complainants. Having all such data to hand would assist in determining whether the issue requiring attention by police oversight agencies in any one area is individual complainants (reflected in repeat complainants) or individual police officers (reflected in repeat police suspects). Moreover, the dominant pattern of alleged incidents occurring away from complainants' residences suggests that future studies must provide a wider frame than the local street corner society, as traditionally relied upon in crime studies, in trying to account for complainant and police iterations and complaint incidents. Consequently, based on the findings here, while still referenced in studying crime locations (see Hipp 2016), application of the 'distance decay' theoretical framework to explain allegations of misbehaviour against police officers appears less appropriate than what might be called a 'distance growth' one. As used here the latter denotes that, up to a point, complaints grow in number the further away an incident occurs from a complainant's residence ${ }^{5}$. This conclusion implies a need to improve upon complaint theory and that borrowing existing theory from studies of crime may not suffice.

As to the nature of complaints, the third and fourth research questions addressed different aspects of this theme. Complaints did diminish in seriousness as distance from complainant residence point grew, i.e. were located closer to the complainant home in each station area. Studies of crime events have shown that violent crimes occur closer to, i.e. are more localised 
than, property crimes (Chamberlain and Hipp, 2015). The finding in this study reflected that pattern. It suggests complainants/ deviant police officers being emboldened within areas with which they are familiar and/or with persons they know and with whom they have some history. Future research should aim to clarify this further. Meanwhile, the fourth and final research question had queried whether there was any clustering of allegation types in RAPID compared to non-RAPID areas. While RAPID areas did display the greater proportion of serious allegation types, these individual allegations occurred in isolation from similar actions. This finding could be interpreted in one of two ways. Either, it meant that the most serious forms of garda misbehaviour were not common outside the RAPID areas and even within these areas, they were not so concentrated at particular micro locations as to give rise to any concerns of systemic targeting. Alternatively, the allegation classification remained just that, a form of labelling by GSOC; it did not signify confirmed garda misconduct. The allegation type clustering therefore could be interpreted as a reflection of complainants in RAPID areas being more prone towards making exaggerated complaints. Yet, this possibility is mitigated by the fact that under the 2005 Act the knowing provision of false information by all garda suspects, complainants, and witnesses in contact with GSOC renders them liable to prosecution, a condition made known to all complainants ${ }^{6}$. Overall, in relation to the finding here of more serious allegations being more commonly confined to low neighbourhoods, deciding whether this is due to police officer conduct or allegation labelling by GSOC is not aided by the low substantiation rates recorded against complaints in Ireland. These have consistently been below $2 \%$ since 2007 . A clear determination is also hampered by the small body of research work on investigative standards within police oversight bodies (Sanders et al., 2010; Jones, 2009). 
Looking to the station level, clustering of allegation types only occurred in Duville station. If replicated across all Garda stations, it would present as good news for local police managers in that allegations of concentrated, serious garda misconduct are the exception rather than the norm. However, measured against Kelly and Teljeur's national deprivation index noted in the Data and Methods section, Duville presented as being the most unequal of the three stations. It also recorded the most uneven scores for social fragmentation, signifying higher variation in deprivation-affluence across neighbourhoods within the station catchment area. This highlighted another gap in current research knowledge. More research attention should be directed to the degree of differentiation in police officer conduct between micro areas within a single police station area depending on the income inequality and social fragmentation profile of these micro areas. Such analysis requires the combining of demographic, police officer (and police agency) performance and complaint data.

An initial test of this hypothesis, that greater variation in deprivation/income inequality might lead to more varied policing styles, seems supported by secondary data for local areas in England and the USA. In England, for example, after the 2011 riots academics queried why certain areas characterised by deprivation had rioted and others not (Newburn, 2016). Kingston-upon-Hull and Middlesborough both record high deprivation levels (Department for Communities and Local Government, 2015). Yet, Hull features lesser income inequality than Middlesborough. (Office for National Statistics, 2016) and Hull's local police force Humberside Police- was most recently judged 'good' at treating its public with respect (HMIC, 2016) and it also fared well on complaints per 1,000 employees (IPCC, 2016). Middlesborough, by contrast, is located within the Cleveland Police force catchment area which most recently placed among the worst performers at treating people with fairness and respect (HMIC, 2016) and recorded the highest allegations per 1,000 police employees 
(IPCC, 2016). In the USA greater inequalities too seem to produce greater variations in policing styles. Demographic data at metropolitan or lower county level, for example, point to some of the greatest income inequality nationally being present in Chicago, Los Angeles, New York and Miami (Posey, 2016), cities whose police conduct and oversight arrangements have come in for renewed scrutiny in recent years.

Overall, it is concluded that social disorganization as a theoretical framework for understanding the geography of alleged police misbehaviour played a role in explaining the type of complaint but not volume of complaints that emerged against Irish police. Based on station level socio-demographic data there was no clear relationship between crime levels and complaint numbers or between social housing stock, residential mobility and proportion of non-white persons and complaints. The Garda station area generating the greatest volume of complaints relative to population (Hometown) was neither the most nor the least socially disorganized of the three. This inconsistency was borne out by 2011 Irish Census data at police division and county level which suggested that population change, density, area stability (i.e. inward migration), and housing tenure could not account conclusively for higher numbers of complaints. Galway, for example, had a higher population growth rate in the years 2006-2011, i.e. the years between one census and the next, and a higher proportion of non-Irish born residents than Limerick and Cork (CSO, 2012; CSO, undated). Noting also a link between housing ownership and pro-social attachment to an area's social fabric (Morenoff et al., 2001), at the 2011 Census Galway had a greater volume of rental accommodation as a proportion of all housing occupancy than Limerick, Cork and Dublin (CSO, undated). Despite this, within GSOC annual reports Limerick, Cork and Dublin routinely feature as the subject of more complaints. 
If social disorganization does not provide a wholly adequate explanation for the complaint patterns observed, what might explain them? One answer could be the variation in police culture across a police agency and particularly at lower organisational levels (Hickman and Piquero, 2009). In that regard accounts of group or pack behaviour within policing have been noted from New Zealand (Bazley, 2007) to Canada (Alain, 2004). In the Irish case, Gordon (2007) pointed to the significance of the informal schooling of new gardaí once on the beat through their adoption of learned practices from peers; a shared outlook that manifested in low levels of garda co-operation with the GSCB, the previous Irish police complaints body, when 150 gardaí were challenged on their conduct at a public protest in 2002. Applying this perspective to complaint data examined here, a suggestion of repeated, local police officer misbehaviour seemed supported by the type of incidents that occurred in RAPID areas within Scotsburg, Hometown and Duville stations. To improve upon this interpretation better data are needed. On the one hand, this would take the form of data on personnel and complainants. As things stand however, police oversight agencies do not always capture and report upon personnel and complainant data. The extent of the missing data problem within the Irish oversight model, for example, is evident in that garda details were missing on $24 \%$ of all allegations, $33 \%$ of the most serious investigation cases and $88 \%$ of all death/serious harm referrals from the Garda Commissioner (section 102 of the Act) in 2013. On the other hand, given cyclical concerns about policing across jurisdictions, collection and use of better data on police culture are also warranted. Recently, Marenin (2016) has drawn attention to this point highlighting that all police reforms will matter little if they conflict with the culture in place. It is more likely that police officers may act under the belief that some form of street justice must be served. As of June 2017, the terms of the thirteenth commission, tribunal, independent inquiry, review and investigation into garda misconduct since the 2005 overhaul 
were being finalised by the Irish government. Marenin's thesis therefore underscores the currency of improving upon data relating to police culture.

Notwithstanding the above, further efforts to incorporate complaint geography within a general theory of police misbehaviour, will also have to cope with why, with a documented history of conflictual relations with Irish police officers, did not even more complaints emerge from or occur in RAPID areas examined. GSOC's unpublished 2010 Public Attitudes Survey recorded that persons from lower socio-economic backgrounds were more dissatisfied and more willing to make a complaint if an interaction with a garda merited it. In answering why fewer complaints emerged than expected, it appears unlikely that such areas were unaware of the police oversight agency or had direct/vicarious experience of GSOC. GSOC had conducted print media and radio awareness campaigns at its commencement in 2007 and it received a high initial complaint load. Separately, GSOC's Public Attitudes Surveys for 2010 and 2012 showed that above $65 \%$ of all social class groupings had heard of it (GSOC, unpublished). The lower than expected incidence of complaints from RAPID areas also could not be attributed to people viewing garda action as something other than constituting misbehaviour. Each Garda division, for example, has attracted complaints since 2007, a fact annually reported on by local press. A third possible explanation relates to the cost versus benefit trade-off in making a complaint. Grace and Bucke (2009) identified the burden of making a police complaint as the most common reason for not formalising a grievance against an officer, so much so that it reduces possible complaint volumes by $75 \%$ (John Howard Society of Alberta, 2005). Unpublished GSOC Public Attitude Survey data for 2010 found that a similar result applies in the Irish case. Bringing these observations together, the best explanation for the high but not overwhelming incidence of complaints from RAPID areas is arguably that, subjected to more serious police officer misbehaviour and having had a 
direct/vicarious experience of GSOC, not all persons in the most socially disorganized or low neighbourhoods with a grievance believed that complaining was worth the effort.

This conclusion highlights two broad areas for future analysis of complainants in socially disorganized/ low neighbourhoods. The first concerns who complains and who does not. Socio-demographic profiles of police complainants provide part of the answer (Lersch, 1998; Liederbach et al., 2007; Docking and Bucke, 2006), complainants in the USA and EnglandWales being young, male, non-white and, in the USA, earning below median earnings. It is motivations for complaining among residents of socially disorganized areas, as against not complaining, though that remains the bigger issue. Finding out how extensive is the incidence of non-complaining in socially disorganized neighbourhoods and, thereafter, what are the motivations for not complaining merit more scholarly attention.

The second area for future research is the perspective of socially disorganized areas on how the complaint mechanism is arranged in law and implemented in practice. Low neighbourhoods are said to be least able to hold police officers and agencies to account (Kane, 2005: 492); they are characterised by high levels of legal cynicism (Sampson and Bartusch, 1998), i.e. view police officers as illegitimate and unresponsive. If residents in high legal cynicism, low neighbourhoods do not differentiate between the police and other state agencies, including police overseers, it suggests an obvious impact on the effectiveness of the latter and implications for criminal justice system viability more broadly. In that regard, a steady downward pattern in complaints submitted to GSOC since 2008 must be borne in mind. Allowing for the possibility that this decline reflects an improvement in general garda behaviour, it could equally, and alternatively, reflect declining public belief in the current oversight model's ability to address garda misconduct. This would resonate with literature 
pointing to a decline in public support for oversight models over time where complainants feel that their grievance is not receiving due and fair attention (Worrall, 2002). In that regard, it must be noted that police oversight practice in Ireland has been circumscribed in defining and responding to police misbehaviour. This is evidenced in that a code of ethics, legislated for by the 2005 Act, and which might have clarified the parameters of garda misconduct more than the Act did, was still not in place by 2017. Furthermore, ahead of its introduction the national parliament removed the connection between a breach of the Code and subsequent sanction via the Discipline Regulations, thereby likely rendering the Code ineffectual.

Quite apart from any academic gains in identifying some appropriate theoretical frame through which to account for police officer misconduct and its geography, much scope remains for better application of GIS by police overseers than is performed at present. Areafocused and/or police-involved programmes exist in France (Zones Securités Prioritaires), England-Wales (Vulnerable Localities Index), Northern Ireland (the deprivation measure) and the USA (Promise Zones program) for instance. Each of these jurisdictions continues to record serious police officer misbehaviour across 2017. Yet, police overseers do not seem to draw upon the public programmes mentioned in structuring analysis of police officer deviance. The consequence of failing to conduct analysis of and conceptualise police officer misconduct geography leaves police oversight bodies open to criticism about how they function and validate what they do. Extending GIS use in the manner used in this article could serve to provide police overseers with the groundwork for targeted police officer training and police deployment reforms, boosting their reputations in turn.

The potential for better GIS use also applies to police agencies. A decision by police management to use GIS/GPS tools to determine location and time spent by officers in distinct 
areas would address two contemporary concerns within the policing domain. The first of these is the smart deployment of police officers to respond better to crime, particularly given sustained budgetary pressures on many police agencies, ones that limit prospects of further recruitment and police feet on the ground. Second, increased demands for scrutiny of police officer conduct, borne of individual police officer and line manager failings in the past (Chemerinsky, 2001; Office of Police Integrity, 2008) bring forward police efforts to introduce new technologies (Worrall, 2002), reflected most recently in the rollout of body worn camera programmes. These in turn introduce the potential for better analysis of patrol movements. Hipp (2016) touches on the issue of greater and better data generation, through GPS means, in relation to developing a general theory of spatial crime patterns. This article has sought to make the case for similar thinking in relation to spatial patterns of police officer misconduct.

\section{Limitations and Opportunities}

Findings described here relate only to complaints made, not the totality of police operations in selected station areas, and the complaint volumes analysed were quite small and undermined by missing data. Future research on police misconduct geography would benefit from using larger complaint loads and would be improved upon by the addition of the temporal occurrence of incidents, what Hart and Miethe (2015) term 'hot times'. Reflecting findings in other studies (Hart and Waller, 2013), this article also highlighted a lack of congruence between statistical unit, Garda and RAPID boundaries in shape and everyday cognition. Future research into police officer misconduct would benefit from ongoing development of units of analysis that chime with the sensibilities of service providers (Haining and Law, 2007) and so enable better police agency reform discourse. Finally, in looking to distinguish between police officer misconduct in low neighbourhoods and others, 
future studies would gain from data on police patrol activity within the deprived/affluent areas of precincts.

\section{Conclusion}

Studies of the geography of crime committed by non-police persons have examined residence point, incident location point and offence type, thereby enabling better police responses. Studies of police misconduct to date have not followed suit. Using data from three stations (precincts) the current study made four discoveries of practical use to police and police oversight agencies. The most socially disorganized or low neighbourhoods of Irish police stations submitted high but not dominant proportions of complaints. Whether from resource affluent or low neighbourhoods, incidents of alleged police officer misconduct more frequently occurred at some distance from the complainant's home and allegation seriousness declined the greater this distance. Finally, more serious allegation types arose in low neighbourhoods but did not cluster together within such areas, thereby suggesting no clear pattern of targeting by Irish police officers.

Placing this article's numerical findings into the context of global developments, a more regular focus on police officer misconduct from San Francisco to Hong Kong in recent times is accompanied by demands for better insight into patterns and theory by which to understand and address the why, where, how and what of police aberrations. The findings here make the case that framing the geography of police officer misconduct by reference to existing crime theories, such as distance decay and social disorganization, may not suffice. There is a need for research to push beyond the frontiers of current knowledge, to better map the influence of income inequality and police culture on the degree of variation in police officer conduct at local level and to account for the possibility that more complaints and complaints of a more 
serious nature may exist in low neighbourhoods. It is only through researchers and, especially police oversight agencies, asking more probing questions than heretofore that the full extent of police officer misconduct in Ireland, and elsewhere, will be clarified. To continue to do otherwise begs questions as to the commitment towards improving police officer conduct and policing more widely by consequence.

\section{Notes}

1. GSOC did not report on allegation locations beyond 2013.

2. Aliases intended to safeguard against possible attempts to mitigate any findings by reference to unstructured, anecdotal accounts of the stations concerned.

3. Those parts of the RAPID area not falling within each station area boundary were manually removed ahead of analysis using Editor tools in ESRI's ArcMap. A similar necessity would have applied if another areal unit had been substituted for RAPID because Garda station boundaries do not always match those of other administrative entities/ programmes such as Electoral Districts.

4. Garda Síochána and GSOC work to date have been at polygon level only, i.e. reporting a single figure for an entire station catchment area, and a recent, wide-ranging Irish criminology textbook (Healy et al., 2016) makes no explicit use of GIS.

5. If crime studies were to map the incident location of all crime, i.e. street and suite crime, the distance decay theory might also look very different and perhaps closer to the "distance growth" perspective presented here.

6. It must be borne in mind, equally, that in countering any complaint police may subsequently exaggerate the situation they faced with the aim of justifying their use of more serious actions (Marenin, 2016). 


\section{References}

Alain, M. (2004). 'Une mesure de la propension des policies Québécois à denouncer des comportements dérogatoires, elements de culture policière et cultures organisationnelles'. Déviance et Société, Vol. 28: 3-31.

Bazley, M. (2007). Commission of Inquiry into Police Conduct. Wellington: Commission of Inquiry into Police Conduct.

Bruinsma, G.H.N. (2007). 'Urbanization and Urban Crime: Dutch geographical and environmental research.' Crime and Justice, 35: 453-502.

Chamberlain, A. W. and Hipp, J. R. (2015). 'It's all relative: concentrated disadvantage within and across neighborhoods and communities, and the consequences for neighborhood crime.' Journal of Criminal Justice, No. 43: 431-443.

Chappell, A.T. and A.R. Piquero (2004). 'Applying social learning theory to police misconduct'. Deviant Behavior, Volume 25, No. 2: 89-108.

Chemerinsky, E. (2001). 'An Independent Analysis of the Los Angeles Police Department's Board of Inquiry Report on the Rampart Scandal'. Loyola of Los Angeles Law Review, 34: $545-655$

Commission Nationale de Déontologie de la Sécurite (2011). Rapport 2010. Paris: CNDS. Central Statistics Office (undated). Census 2011 Small Area Population Statistics CSV Downloads. Available at http://www.cso.ie/en/census/census2011smallareapopulation statisticssaps/. Viewed 1 February 2017.

Central Statistics Office (2012). Profile 4 The Roof Over Our Heads. Dublin: CSO.

Dean, G., Bell, P. and Lauchs, M. (2010). 'Conceptual framework for managing knowledge of police deviance.' Policing \& Society, Vol. 20, No. 2 (June): 204-222.

Department for Communities and Local Government (2015). File 1: index of multiple deprivation. Available at www.gov.uk. Viewed 20 March 2017. 
Department of the Environment, Community and Local Government (2011). Value for Money and Policy Review of the Clár and RAPID Leveraged Expenditure Approach. Dublin: Department of the Environment, Community and Local Government.

Office for National Statistics (2015). Annual Survey of Hours and Earnings-Place of Residence by Local Authority-ASHE: Table 8. Available at www.ons.gov.uk. Viewed 20 March 2017.

Docking, M. and Bucke, T. (2006). Confidence in the Police Complaints System: a survey of the general population. IPCC Research and Statistics Series: Paper 2. London: IPCC. Fitzpatrick Associates (2006). Evaluation of the RAPID Programme: final report. Dublin: Department of Community, Rural and Gaeltacht Affairs.

Grace, K. and Bucke, T. (2009). Public Annoyance and Complaints About the Police: findings from the 2006/07 British Crime Survey. London: IPCC.

Garda Síochána Complaints Board (1988). Annual Report 1987. Dublin: GSCB.

Gordon, C. (2007) 'Training and Development of Student Probationer Gardaí'. Communiqué Management Journal, June. Available at www.garda.ie. Viewed 1 February 2017. GSOC (2013). Annual Report 2012. Dublin: GSOC. Haining, R. and Law, J. (2007). 'Combining police perceptions with police records of serious crime areas: a modelling approach'Journal of the Royal Statistical Society Series A (Statistics in Society), Volume 170, Number 4: 1019-1034.

Hart, T. C. and Miethe, T. D. (2015). 'Configural Behavior Settings of Crime Event Locations: toward an alternative conceptualization of criminogenic microenvironments.' Journal of Research in Crime and Delinquency, Volume 52(3): 373-402.

Hart, T. and Waller, J. (2013). 'Neighborhood boundaries and structural determinants of social disorganization: examining the validity of commonly used measures'. Western Criminology Review, 14(3): 16-33. 
Healy, D., Hamilton, Daly, Y. and Butler, M. (eds.) (2016). Routledge Handbook of Irish Criminology. London: Routledge.

Her Majesty’s Inspectorate of Constabulary (2016). Peel Assessments 2016. Available at www.justiceinspectorates.gov.uk. Viewed 20 March 2017.

Hickman, M. J. and Piquero, A. R. (2009). 'Organizational administrative and environmental correlates of complaints about police use of force'. Crime \& Delinquency, Volume 55, Number 1: 3-27.

Hipp, J.R. (2016). 'General Theory of Spatial Crime Patterns.' Criminology, Volume 54, Number 4.: 653-679.

IPCC (2016). Police Complaint Statistics for England and Wales 2015/16. London: IPCC. John Howard Society of Alberta (2005). An Examination of Citizen Involvement in Complaints Regarding Police. Available at www.johnhoward.ab.ca. Viewed 1 February 2017.

Jones, D. (2009). Conducting Administrative, Oversight \& Ombudsman Investigations. Aurora: Canada Law Book.

Kane, R.J. (2005). 'Compromised Legitimacy as a Predictor of Violent Crime in Structurally Disadvantaged Communities.' Criminology, Volume 43, Issue 2: 469-498.

Kelly, A. and Teljeur, C. (2013). The National Deprivation Index For Health \& Health Services Research - Update 2013, Dublin: TCD.

Kubrin, C. E. and Weitzer, R. (2003). 'New Directions in Social Disorganization Theory.' Journal of Research in Crime and Delinquency, Volume 40, Number 4, November: 374-402. Lersch, K. M. (1998). 'Police Misconduct and Malpractice: a critical analysis of citizens' complaints.' Policing: An international Journal of Police Strategies \& Management, Vol. 21, No. 1: 80-96. 
Liederbach, J., Boyd, L. M., Taylor, R. M. and Kawucha, S. W. (2007). 'Is it an inside job? An examination of internal affairs investigation complaint files and the production of nonsustained findings'. Criminal Justice Policy, Volume 18, Number 4: 353-377.

Loftus, B. (2012). Police Culture in a Changing World. Oxford: Oxford University Press. Marenin, O. (2016). 'Cheapening death: danger, police street culture, and the use of deadly force'. Police Quarterly, Volume 19(4): 461-487.

Morenoff, J. D., Sampson, R. and Raudenbush, S. W. (2001). Neighborhood Inequality, Collective Efficacy and the Spatial Dynamics of Urban Violence, Report No.00-451. Ann Arbor: University of Michigan.

Morris, F. (2004). Report of the Tribunal of Inquir. Set up pursuant to the Tribunal of Inquiry (Evidence) Acts 1921-2002 into Certain Gardai in the Donegal Division. Report on Explosives 'finds' in Donegal. Dublin: Government Publications.

Newburn, T. (2014). Police Integrity and Corruption- literature review. London: HMIC. Newburn, T. (2016). 'Reflections on why riots don't happen'. Theoretical Criminology, Vol. 20, Issue 2: 125-144

NYC Civilian Complaint Review Board. (2012). Annual Report 2012. New York: CCRB. Office of Police Integrity (2008). Armed Offenders Squad-a case study. Melbourne: OPI. Oireachtas (2004). Parliamentary Debates Seanad Éireann Volume 178, No. 27, 14 December.

Police Ombudsman for Northern Ireland (2013). Statistical Report of the Police Ombudsman for Northern Ireland, six-monthly update to September 2013. Belfast: PONI.

Posey, K. (2016). Household Income: 2015. American Community Survey Briefs,

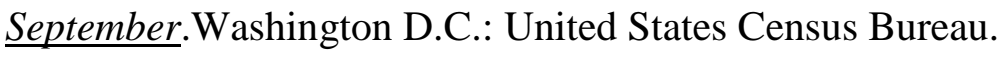

Rengert, G. F., Piquero, A. R and Jones, P. R. (1999). 'Distance Decay Re-examined.' Criminology, Volume 37, No. 2: 427-445. 
Robitaille, E., Séguin, A-M., Lacourse, E., Vitaro, F. and Tremblay, R.E. (2011).

'Désavantage Socioéconomique du Quartier et Comportements Antisociaux des Adolescents: quelle est l'échelle spatiale la plus probante?' Revue canadienne des sciences $d u$ comportement, Volume 43, Issue 2: 78-88.

Rossler, M. T. and Terrill, W. (2012). 'Police Responsiveness to Service-Related Requests'. Police Quarterly, Vol. 15, No. 1: 3-24.

Sampson, R.J. and Bartusch, D.J. (1998). 'Legal Cynicism and (Subcultural?) Tolerance of Deviance: the neighborhood context of racial differences'. Law \& Society Review, Volume 32, No. 4: 777-804.

Sanders, A., R. Young and M. Burton (2010). Criminal Justice. Oxford: Oxford University Press.

Shaw, C.R. and McKay, H.D. (1969). Juvenile Delinquency and Urban Areas: a study of rates of delinquency in relation to differential characteristics of local communities in American cities. Illinois: The University of Chicago Press.

Smith, D. J., McVie, S., Woodward, R. Shute, J., J. Flint and L. McAra (2001). The Edinburgh Study of Youth Transitions and Crime: key findings at ages 12 and 13 . Available at http://www.esytc.ed.ac.uk/findings/published. Viewed 1 February 2017.

Steenbeek, W. and Weisburd, D. (2016). 'Where the Action is in Crime? An examination of variability of crime across different spatial units in The Hague, 2001-2009.' Journal of Quantitative Criminology, Volume 32: 449-469.

Sun, I. Y., Payne, B.K. and Wu, Y. (2008). 'The Impact of Situational Factors, Officer Characteristics and Neighborhood Context on Police Behaviour: a multilevel analysis.' Journal of Criminal Justice, Volume 36, Issue 1: 22-32.

Sutherland, E.W. (1940) 'White Collar Criminality.' American Sociological Review, Vol. 5, No. 1: 1-12. 
Worrall, J. (2002). 'If you build it, they will come: consequences of improved citizen complaint review procedures'. Crime \& Delinquency, Volume 48: 355-379. 